\title{
Children's heart and COVID-19: Up-to-date evidence in the form of a systematic review
}

\author{
Giulia Sanna $^{1} \cdot$ Gaia Serrau $^{1} \cdot$ Pier Paolo Bassareo ${ }^{2,3}$ (D) Paola Neroni $^{1} \cdot$ Vassilios Fanos $^{1} \cdot$ Maria Antonietta Marcialis $^{1}$
}

Received: 25 April 2020 / Revised: 17 May 2020 / Accepted: 20 May 2020 / Published online: 30 May 2020

(C) Springer-Verlag GmbH Germany, part of Springer Nature 2020

\section{Abstract}

The new coronavirus disease outbreak in 2019 (COVID-19) represents a dramatic challenge for healthcare systems worldwide. As to viral tropism, lungs are not the only COVID-19 target but also the heart may be involved in a not negligible percentage of the infected patients. Myocarditis-related cardiac dysfunction and potentially life-threatening arrhythmias are the main aftermaths. A few studies showed that myocardial injury in adult patients is often linked with a fatal outcome. Conversely, scientific evidence in children is sparse, although several reports were published with the description of a cardiac involvement in COVID19 paediatric patients. In these young subjects, a background of surgically treated congenital heart disease seems to be a predisposing factor.

Conclusion: This systematic review is aimed at summarizing all COVID-19 cases with a cardiac involvement published in paediatric age and trying to explain the underlying mechanisms responsible for COVID-19-related myocardial damage.

What is Known:

- Coronaviruses proved to be able to jump from animals to humans.

- The outbreak of COVID-19 started from China (Dec 2019) and became pandemic.

What is New:

- Even in childhood, COVID-19 is not without the risk of cardiac involvement.

- Myocarditis, heart failure, and arrhythmias are among the possible manifestations.

Keywords Coronavirus $\cdot$ COVID-19 $\cdot$ Severe respiratory distress syndrome $\cdot$ Heart $\cdot$ Cardiovascular $\cdot$ Myocarditis

\section{Abbreviations}

COVID-19

Coronavirus disease 2019

SARS-CoV-2 Severe acute respiratory syndrome coronavirus 2

SARS

Severe acute respiratory syndrome
RNA

ACC

AHA

EACVI
Ribonucleic acid

American College of cardiology

American Heart Association European Association of CardioVascular Imaging

Giulia Sanna and Gaia Serrau contributed equally to this work.

Communicated by Peter de Winter

Pier Paolo Bassareo

piercard@inwind.it

Giulia Sanna

giuliasanna6@hotmail.com

Gaia Serrau

gaiaserrau@gmail.com

Paola Neroni

paolaneroni123@gmail.com

Vassilios Fanos

vafanos@tiscali.it
Maria Antonietta Marcialis mmarcialis@aouca.it

1 Neonatal Intensive Care Unit, University of Cagliari, Cagliari, Italy

2 Mater Misericordiae University Hospital and Our Lady's Children's Hospital Crumlin, University College of Dublin, Dublin, Ireland

3 Mater Misericordiae University Hospital, University College of Dublin, Eccles St, Inns Quay, D07 R2WY Dublin, Republic of Ireland 
ECG

MRI

Electrocardiogram

Magnetic resonance imaging

\section{Introduction}

The outbreak of severe acute respiratory syndrome coronavirus 2 (SARS-CoV-2), which is responsible for the so called coronavirus disease, started from December 2019 (COVID19), in Wuhan, province Hubei, China. Since then, COVID19 has been spreading abruptly all over the world with scary consequences for global health. That is the reason why it was declared as pandemic since 11 March 2020.

COVID-19 main target are airways and lungs. It is spread by human-to-human transmission via airborne droplets or direct contact. Up to 14 days are required for its symptoms to appear. In a vast majority of the patients ( $80-85 \%)$, symptoms can be mistaken for those of flu or cold, with loss of smell and taste, sneezing, cough, fever, and shortness of breath. However, a not negligible percentage of those who are infected (15-20\%) present severe or critical symptoms, i.e. with pneumonia and severe acute respiratory distress, which can get worse even in a very short time (hours). Bilateral lung involvement with ground-glass opacity is the most common finding from computed tomography images of their chest [1].

COVID-19 seems to be less aggressive in paediatric patients and related symptoms milder than in adults. The most common symptoms in children are mild fever, cough, rhinorrhoea, and sore throat. Gastrointestinal symptoms like vomit and diarrhoea are possible as well [2].

In a recent Chinese report, a cardiac involvement was described in $12 \%$ of adult patients [3], while in another study from the same country arrhythmias and myocardial injury were reported in $16.7 \%$ and $7.2 \%$ of them [4].

\section{Purpose of the review}

This systematic review was aimed at identifying the link between COVID-19 and cardiac involvement in paediatric age.

\section{Research strategy}

Pubmed/Medline, Scopus, and Web of Sciences databases were searched electronically from their inception up to 16 April 2020 utilizing Boolean operators and combinations of word variants for "coronavirus" or "COVID-19" or "severe acute respiratory syndrome" or "SARS-CoV-2" and "paediatric," "children," "heart," "cardiac," "cardiovascular," and "pregnancy." The search and selection criteria were restricted to English language (at least the abstract).

\section{Other sources}

Reference lists of the identified papers and relevant manuscripts were examined. Emails were sent to the authors of the above articles for further information when needed. Five reviewers were calibrated for the identification of eligible studies (Bassareo PP, Neroni P, Sanna G, Serrau G, and Marcialis MA) by a sixth reviewer (Fanos V) through successive stages of quintuplicate independent screening among randomly selected titles and abstracts in groups of five, until a complete intra-examiner agreement was obtained ( $k$ scores from the first to the last calibration exercise: $0.82,0.86$, 0.93 , and 1). A parallel, triple-blind screening procedure of all titles and abstracts retrieved by the electronic search was performed by the above stated five reviewers. The titles and abstracts were screened for subject importance. Studies that were not definitively excluded on the basis of abstract information were also selected for full-text screening. The reviewers examined the full text of all relevant researches to evaluate the possibility of inclusion. In the case of disagreement over study inclusion, a discussion was held with the sixth reviewer (Fanos V) to reach an agreement. Studies were eligible for inclusion on meeting the following criterion: all studies concerning cardiac involvement in children with COVID-19 with no limitation on the period of publication. The criteria of exclusion were as follows: (i) studies not focused on the topic selected, (ii) papers in a language other than English, (iii) duplicates, and (iv) studies not available from libraries for full-text assessment.

\section{Data extraction}

Five reviewers (Bassareo PP, Neroni P, Sanna G, Serrau G, and Marcialis MA) independently extracted data using a structured form specifically developed for this review. The following information was extracted from each included study: authors, year of publication, type of paper, cardiovascular involvement in the setting of newborns, and/or children suffering from COVID-19 infection. Any discrepancy that occurred during data extraction was solved by consensus or discussion with the sixth reviewer (Fanos V).

\section{Data synthesis}

As this systematic review included heterogeneous study designs and sources, the results and key information obtained were summarized by means of a narrative approach. 


\section{Results of literature search}

The literature search yielded a total of 187 primary studies, of which 96 (56 duplicates) were excluded following the screening of the title and abstract. Ultimately, 91 studies were included for full-text assessment based on a relevant title and abstract. A total of 68 were excluded as they failed to meet general inclusion criteria, and 3 were not available from online libraries. As a result, 20 studies met the inclusion criteria, and an additional 26 papers were included after checking the references of the relevant selected reviews and studies. A flow diagram of the study selection process is presented in Fig. 1.

The characteristics and demographic features of the studies focused on a cardiovascular involvement in COVID-19 affected children are summarized in Table 1.

\section{Scientific evidence}

Data relating to COVID-19 in paediatric age are still quite sparse, and few severe cases have been reported in children so far. Notwithstanding children apparently are less prone to develop severe symptoms of COVID-19; a cardiac involvement was described in a few of them, thus showing that the heart is a possible target of the disease at this age range as well. In a recent report, the case of a 55-day-old female infant with multiple organ damage, heart included, has been described. Along with ground glass opacities at her lungs detected by computed tomography, tachycardia (150-170 bpm) was detected [5]. Not only, but at day 4th from admission, an increase in troponin and cardiac enzymes was reported as well. Since day 7 th, however, the patient's general conditions improved and 3 days later troponin and cardiac enzymes normalized along with respiratory distress.

In another small case series of eight severe or critically ill patients infected by SARS-CoV-2, the case of a 13-month male child who developed heart failure, septic shock, coagulopathy, and multiple organ failure was described [6].

In adult patients, COVID-19-related mortality is higher in those with pre-existing cardiovascular disease. The higher the number of cardiovascular comorbidities, the higher and earlier the mortality, as pointed out in the recent study by Madjid et al. Factors associated with increased mortality included male gender, elderly, and the presence of comorbidities such as high blood pressure, diabetes, cardiovascular, and cerebrovascular diseases [7].

Similarly, COVID-19 clinical course is worse in children with underlying conditions, including those previously treated surgically for congenital heart disease, though no deaths were reported to date [8]. Similar conclusions are in the study by $\mathrm{Xia}$ et al. [9], since 7 children out of the twenty enrolled were affected by a previous congenital or acquired pathology. In particular, two of them survived previous surgery for atrial septal defect closure. On balance, COVID-19-related virus pneumonia in these children was mainly mild and, as to laboratory findings, a rise in procalcitonin was detected in about $80 \%$ of them. Conversely, an increase of this protein is not common in adults. A past medical history of congenital heart disease, bronchopulmonary hypoplasia, respiratory tract abnormalities, haemoglobinopathies, severe malnutrition, and immune system deficiency were considered as predisposing factors for severe clinical manifestations of the disease in the Chinese recent experience [10]. In another retrospective study carried out in China and involving 25 children aged less than
Fig. 1 Flow chart of the study selection process

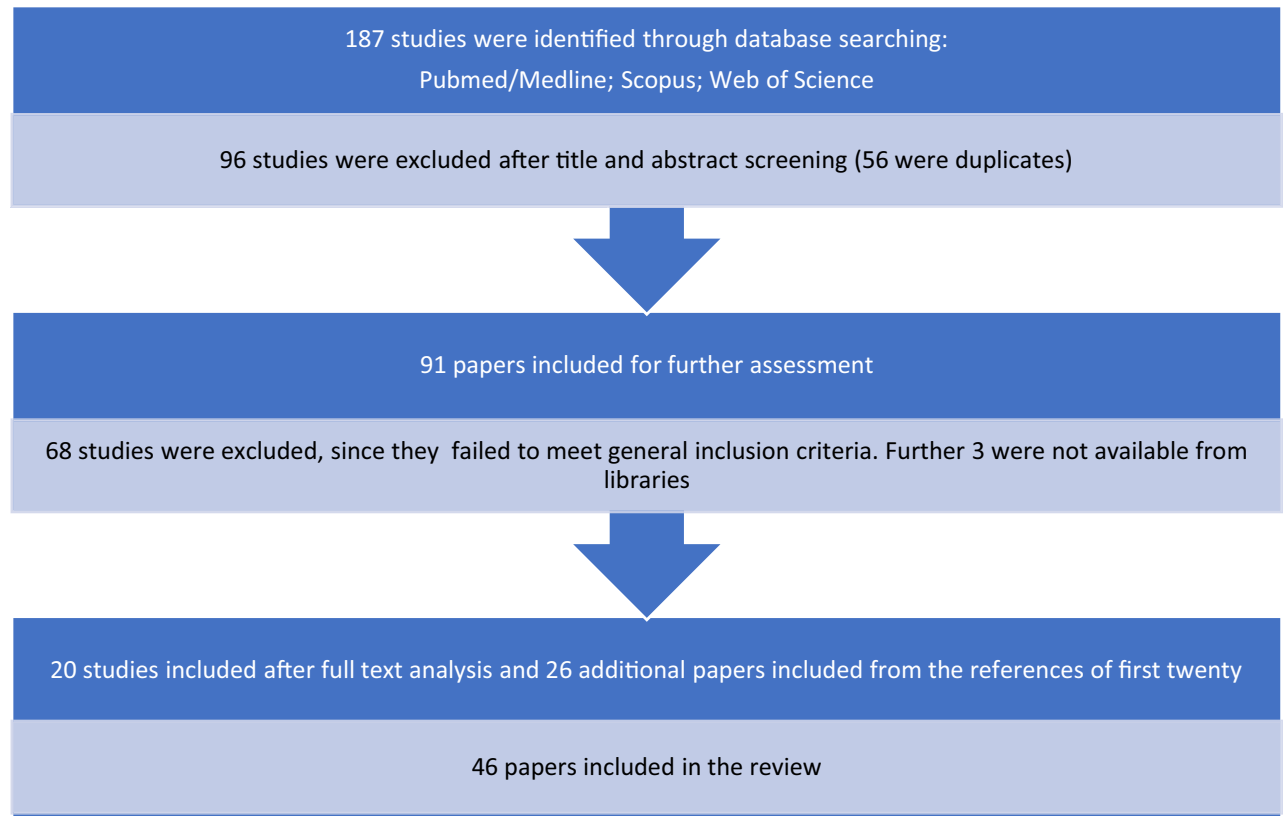


3 years, the most aggressive COVID-19-related infection was registered in two patients previously operated for congenital heart disease (not specified in the paper). These two, with an age of 8 months and 1 year, respectively, were the only patients who developed renal insufficiency and coagulopathies. In addition, they were admitted to the intensive care unit for mechanical ventilation owing to severe pneumonia and concomitant bacterial superinfection. At the time the paper was released, one of the two patients had been already discharged, while the second was still in hospital, though improved from a clinical standpoint [11].

A rise in troponin above 99th percentile was observed in $8-12 \%$ of COVID-19 infected adults [12], most of all when the infection was severe, as showed in the meta-analysis by Lippi et al. [13]. In addition, troponin was higher in the patients admitted to intensive care unit and in those deceased than in subjects admitted to not intensive ward and survivors $[4,14,15]$. Among the infected, a cardiac involvement can be secondary to respiratory distress, in terms of right ventricular failure development and congestion, or due to a direct injury induced by SARS-CoV-2, as testified by a significant increase in cardiac lesion biomarkers in these patients. The first animal model supporting the hypothesis that the viruses belonging to Coronavirus family were able to induce a myocarditis and congestive heart failure dated back to about 30 years ago [16].

In paediatric age, the role of troponin is by far less defined than in adulthood, as very few specific studies were carried out about this issue. However, data have been gathered concerning a troponin I increase as a marker of myocardial injury in children as well $[5,17,18]$.

Owing to COVID-19 outbreak, the American Heart Association (AHA), in collaboration with the American Academy of Pediatrics and other scientific societies, released interim guidance to help rescuers to treat victims in case of cardiac arrest in suspected or confirmed infected children. The core message is highlighting the challenge represented by making that patients with COVID-19 and cardiac arrest receive the best possible chance of survival without compromising the rescuers' safety, since they will be needed to care for future patients [19].

On February 2020, the American College of Cardiology (ACC) released a bulletin highlighting the potential risk of cardiac involvement in patients affected by COVID-19. The ACC suggested a particular precaution in geographic areas amid coronavirus outbreak. Advice as to preventive vaccinations against flu and pneumococcal infections were given. In a more recent update on 6 March 2020, the ACC recommended, when possible, that outpatient examinations in hospitals should be replaced with telemetric monitoring and online consultations [20].

In this specific setting, myocarditis is generally diagnosed by means of clinics, ECG, rise in troponin/cardiac enzymes, 
and echocardiography. Given its wide availability at patients' bedside, echocardiography plays a pivotal role among all cardiac imaging modalities. On the contrary, cardiac MRI is difficult to perform, as COVID-19 young patients are often intubated and this examination is time-consuming. However, a short protocol for acute patients, including only steady-state free precession sequences (for ventricular kinesis and volumes quantification) and T2 mapping (for oedema detection), might be theoretically feasible when using modern magnets that have a reduced time of acquisition of images (i.e. magnets with no less than 32 channels). In this respect, sequences with late gadolinium enhancement should be reserved for the time these patients are discharged from intensive care unit to postintensive ward. For the sake of safety, a minimum number of persons should be involved (patient, radiographer technician, and anaesthesiologist). Magnet and scan room should be carefully disinfected after each examination as well.

When making a comparison with adult patients, whose myocardial involvement is sometimes correlated with the appearance of life-threatening arrhythmias such as ventricular tachycardia and ventricular fibrillation, children with COVID-19 share less harmful rhythm troubles, namely supraventricular tachycardia, premature atrial and ventricular complexes, first degree atrioventricular blocks, and incomplete right bundle branch block [9]. In a recent joint statement from the Heart Rhythm Society, ACC Electrophysiology Council, and AHA Electrocardiography and Arrhythmias Committee it was pointed out that in the acute phase of severe disease, hypoxia and electrolyte unbalance are not rare and can trigger cardiac arrhythmias. Conversely, the exact mechanism responsible for arrhythmias development in COVID-19 children, who suffer from a less severe disease, is still uncertain [21].

Interestingly, notwithstanding the concomitant pneumonia, pulmonary hypertension at cardiac right side was not reported as one of main characteristic of the disease in children [22].

Regarding imaging, COVID-19 pandemic is leading to new and unpredictable challenges, since it is increasing the pressure on cardiac imaging services in general. That is the main reason why the European Association of CardioVascular Imaging (EACVI) released its recommendations on precautions, indications, prioritization, and protection for patients and healthcare personnel involved in imaging during COVID-19 pandemic [23]. The risks linked with the shortage of personnel-because of sickness or redeployment in prioritized areas, such as intensive care units-and the periprocedural transmission of COVID-19 between patients and staff were stressed. Three key-messages were released to highlight that (1) in subjects with suspected or confirmed COVID-19, cardiac imaging should be performed if appropriate at patient's bedside and only if doing so is likely to substantially improve his/her management or be lifesaving; (2) the risk of spreading infection involves staff, equipment, and facilities; and (3) the longer the time required for imaging, the higher the infective risk. In this respect, just a focused echocardiographic study is suggested to shorten the time of exposure. In addition, cardiac MRI should be done only when it is of vital importance for treatment, and the patient can be safely moved for scanning. Since chest computed tomography is often used to confirm SARS-CoV-2-induced pneumonia, it might provide possible synergies and opportunities of cardiac imaging. Indications for foetal echocardiography are the same as before the COVID-19 outbreak.

On balance, the COVID-19 pandemic has forced to reconsider how performing cardiac imaging and minimizing the risk of cross-infection for imagers and patients [23].

A specific diagnostic algorithm was suggested for COVID19 children with suspected cardiovascular involvement [24]. See Fig. 2.

Currently, there is no clinical evidence of vertical transmission from women with a confirmed coronavirus-related illness to their offspring [25]. When the latter are symptomatic at birth, they are more likely to suffer from prematurity, asphyxia, and sepsis, rather than SARS-CoV-2 infection [26].

\section{Pathophysiology}

Pathophysiology of myocardial injury caused by SARS-CoV2 is still unknown, though a few theories were hypothesized. The first is related to a direct myocardial injury, similar to that previously documented in patients with SARS caused by another coronavirus in 2005, when viral RNA in cardiac muscle cells was found $35 \%$ of the infected subjects [27]. The specific mechanism underlying SARS-CoV-2 replication in cardiomyocytes is still under debate, in spite of seeming similar to that of SARS coronavirus [28, 29]. In this respect, recently, it was hypothesized that SARS-CoV-2 may enter myocardial cells simply by binding type 2 angiotensinconverting-enzyme (ACE) receptors on their surface [30-33]. In this respect, those patients taking angiotensinconverting-enzyme inhibitors and angiotensin II receptor blockers (ARB), which inhibit type 1 angiotensinconverting-enzyme receptors while cause an overexpression of type 2, might be at higher risk of cardiac involvement in COVID-19 infection [34]. However, a couple of ongoing trials were recently put in place to rebut this theory [35]. Even though the current health situation is unstable and updates are released almost on a daily basis, the general agreement so far is that patients on such medications should keep on taking them unless there is a clinical indication to stop their use [36]. In comparison with adults, children might be less susceptible to COVID-19 infection because of a reduced function of angiotensin-converting-enzyme type 2 receptors [37]. In addition, paediatric patients are rarely taking angiotensinconverting-enzyme inhibitors and angiotensin II receptor 
Fig. 2 Specific diagnostic algorithm suggested for COVID-

19 children with suspected

cardiovascular involvement

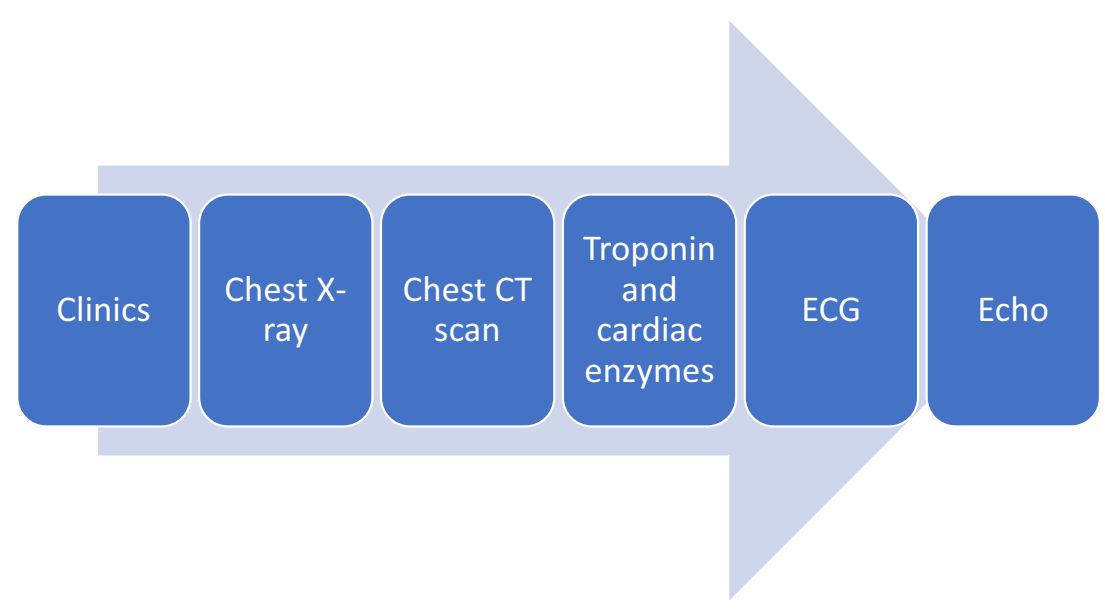

blockers and it may explain why children are affected in a milder way than adults [38].

A second possible mechanism is represented by hypoxia, which was identified in $32 \%$ of the sample by Huang et al. [3]. In another study, about $76 \%$ of the infected patients required oxygen therapy [39]. Pneumonia caused by SARS-CoV-2 may alter alveolar gas exchanges with consequent hypoxia, activate anaerobic metabolism causing metabolic acidosis, and induce oxygen free radical production, thus destroying phospholipid bilayer of myocardial cell membranes. Taken together, all these mechanisms can cause myocardial injury, because of a substantial imbalance between oxygen demand and its availability [40]. In addition, hypoxia itself may cause calcium ions streaming into cardiomyocites, which in turn is responsible for their apoptosis [41].

Inflammation may play a crucial role in myocardial injury as well. COVID-19 patients have increased levels of inflammatory molecules IL- $1 \beta$, IFN- $\gamma$, IP-10, MCP-1, and lymphocyte Th1 activation. Furthermore, inflammatory markers were higher in patients admitted to intensive care unit than in those suffering from less severe forms of the illness [3].

Lastly, even certain antiviral drugs and medications used to prevent from an excessive immune system reaction may damage the heart in these patients, with the appearance of heart failure and arrhythmias. Mechanical ventilation in critically ill children is another possible cause of cardiovascular adverse effects, such as a decrease in cardiac output due to decreased venous return to the right heart, right ventricular dysfunction, and impaired left ventricular distensibility [40, 42]. There is no doubt that an in-depth knowledge of the pathogenetic mechanisms underlying myocardial damage in children with COVID-19 may help to identify those at increased risk, thus expediting their early treatment.

Along with the reduced number and function of angiotensin-converting-enzyme type 2 receptors on cardiomyocytes, other reasons may contribute to explain why children infected with COVID-19 are relatively few to date and their symptoms decidedly mild. In fact, their main clusters of infection are their adult families. When jumping from an individual to another, RNA viruses like coronavirus have a tendency to mutate and make mistakes in replication, with a consequent decline in their virulence $[18,24]$. So, children are infected with second or third or even fourth generation virus and they get milder symptoms. Furthermore, the innate immune response, which is the first response against foreign pathogens, is by far more active in children. Conversely, the adaptive immune system learns to recognize specific pathogens but takes longer to be activated [18, 24]. Other coronaviruses, such as that responsible for SARS, had a similar behaviour. In children, inflammatory cytokines are less activated than they usually are in adults. Finally, children smoke less and have strong self-healing capabilities [18, 43].

Treatment mainly depends on adult patients' clinical experience due to few cases in children. There is no specific drug treatment for COVID-19. Owing to the lack of a specific vaccine against SARS-CoV-2, only symptoms are treated. Transfusion of blood plasma from healed patients may help the still infected to get over the illness. Some of the administered drugs (inotropes, antivirals, antibiotics, hydroxychloroquine, colchicine, azathioprine, and so on), especially when taken in combination therapy, may cause a QT tract prolongation at baseline ECG, which is a well-established marker of potential development of ventricular arrhythmias [44-46].

\section{Conclusions}

Previous studies about the pneumonia outbreak caused by SARS-CoV-2 were mainly based on information from adult populations. Limited data are available for children with COVID-19, especially for infected infants. However, evidence is accumulating rapidly, so these data are likely to be updated soon. 
In addition, the vast majority of published data come from China. Further information from other countries involved in COVID-19 outbreak are probably on the way.

Even though COVID-19 infection in childhood is less common and with milder symptoms than when occurring in adult patients, it is not without the risk of cardiac involvement, especially in the patients with a background of congenital heart disease. In newborns and children, previous cardiac surgery is related with the risk of a more severe form of the disease, being admitted to intensive care unit, and needing intubation as well as mechanical ventilation. In addition, conversely to adulthood, the role of troponin in identifying and quantifying myocardial damage is less definite, because of the small number of studies addressing this issue. Newborns and children are likely to be less susceptible to COVID-19 for reasons such as the reduced function of angiotensinconverting-enzyme type 2 receptors.

On balance, further studies should be carried out in order to more in-depth understand the aftermaths of COVID-19 forms acquired during paediatric age. A tight follow-up is needed in these young individuals [46].

Authors' contributions SG, SGa, PPB, PN, MAM: collected data and wrote the paper; VF: participated in final data screening, revised the paper critically and approved the final version of the paper to be published.

\section{Compliance with ethical standards}

Conflict of interest The authors declare that they have no conflict of interest.

Ethical approval This article does not contain any studies with human participants or animals performed by any of the authors.

\section{References}

1. Zhu N, Zhang D, Wang W, Li X, Yang B, Song J, Zhao X, Huang B, Shi W, Lu R, Niu P, Zhan F, Ma X, Wang D, Xu W, Wu G, Gao GF, Tan W, China Novel Coronavirus Investigating and Research Team (2020) A novel coronavirus from patients with pneumonia in China, 2019. N Engl J Med 382:727-733

2. Zimmermann P, Curtis N (2020) Coronavirus infections in children including COVID-19: an overview of the epidemiology, clinical features, diagnosis, treatment and prevention options in children. Pediatr Infect Dis J 39:369-373

3. Huang C, Wang Y, Li X, Ren L, Zhao J, Hu Y, Zhang L, Fan G, Xu J, Gu X, Cheng Z, Yu T, Xia J, Wei Y, Wu W, Xie X, Yin W, Li H, Liu M, Xiao Y, Gao H, Guo L, Xie J, Wang G, Jiang R, Gao Z, Jin Q, Wang J, Cao B (2020) Clinical features of patients infected with 2019 novel coronavirus in Wuhan, China. Lancet 395:497-506

4. Wang D, Hu B, Hu C, Zhu F, Liu X, Zhang J, Wang B, Xiang H, Cheng Z, Xiong Y, Zhao Y, Li Y, Wang X, Peng Z (2020) Clinical characteristics of 138 hospitalized patients with 2019 novel coronavirus-infected pneumonia in Wuhan, China. JAMA. https://doi.org/10.1001/jama.2020.1585

5. Cui Y, Tian M, Huang D, Wang X, Huang Y, Fan L, Wang L, Chen Y, Liu W, Zhang K, Wu Y, Yang Z, Tao J, Feng J, Liu K, Ye X,
Wang R, Zhang X, Zha Y (2020) A 55-day-old female infant infected with COVID 19 presenting with pneumonia, liver injury, and heart damage. J Infect Dis. https://doi.org/10.1093/infdis/jiaa113

6. Sun D, Li H, Lu XX, Xiao H, Ren J, Zhang FR, Liu ZS (2020) Clinical features of severe pediatric patients with coronavirus disease 2019 in Wuhan: a single center's observational study. World J Pediatr. https://doi.org/10.1007/s12519-020-00354-4

7. Madjid M, Safavi-Naeini P, Solomon SD, Vardeny O (2020) Potential effects of coronaviruses on the cardiovascular system: a review. JAMA Cardiol. https://doi.org/10.1001/jamacardio.2020. 1286

8. Lu Q, Shi Y (2020) Coronavirus disease (COVID-19) and neonate: what neonatologist need to know. J Med Virol. https://doi.org/10. $1002 /$ jmv. 25740

9. Xia W, Shao J, Guo Y, Peng X, Li Z, Hu D (2020) Clinical and CT features in pediatric patients with COVID-19 infection: different points from adults. Pediatr Pulmonol 55:1169-1174

10. Shen K, Yang Y, Wang T, Zhao D, Jiang Y, Jin R, Zheng Y, Xu B, Xie Z, Lin L, Shang Y, Lu X, Shu S, Bai Y, Deng J, Lu M, Ye L, Wang X, Wang Y, Gao L, China National Clinical Research Center for Respiratory Diseases; National Center for Children's Health, Beijing, China; Group of Respirology, Chinese Pediatric Society, Chinese Medical Association; Chinese Medical Doctor Association Committee on Respirology Pediatrics; China Medicine Education Association Committee on Pediatrics; Chinese Research Hospital Association Committee on Pediatrics; Chinese Non-government Medical Institutions Association Committee on Pediatrics; China Association of Traditional Chinese Medicine, Committee on Children's Health and Medicine Research; China News of Drug Information Association, Committee on Children's Safety Medication; Global Pediatric Pulmonology Alliance (2020) Diagnosis, treatment, and prevention of 2019 novel coronavirus infection in children: experts' consensus statement. World J Pediatr. https://doi.org/10.1007/s12519-020-00343-7

11. Zheng F, Liao C, Fan QH, Chen HB, Zhao XG, Xie ZG, Li XL, Chen CX, Lu XX, Liu ZS, Lu W, Chen CB, Jiao R, Zhang AM, Wang JT, Ding XW, Zeng YG, Cheng LP, Huang QF, Wu J, Luo XC, Wang ZJ, Zhong YY, Bai Y, Wu XY, Jin RM (2020) Clinical characteristics of children with coronavirus disease 2019 in Hubei, China. Curr Med Sci. https://doi.org/10.1007/s11596-020-2172-6

12. Lippi G, Plebani M (2020) Laboratory abnormalities in patients with COVID-2019 infection. Clin Chem Lab Med. https://doi.org/ 10.1515/cclm-2020-0198

13. Lippi G, Lavie CJ, Sanchis-Gomar F (2020) Cardiac troponin in coronavirus disease 2019 (COVID-2019). Prog Cardiovasc Dis. https://doi.org/10.1016/j.pcad.2020.03.001

14. Chen C, Chen C, Yan JT, Zhou N, Zhao JP, Wang DW (2020) Analysis of myocardial injury in patients with COVID-19 and association between concomitant cardiovascular diseases and severity of COVID-19. Zhonghua Xin Xue Guan Bing Za Zhi 48:E008. https://doi.org/10.3760/cma.j.cn112148-20200225-00123

15. Zhou F, Yu T, Du R, Fan G, Liu Y, Liu Z, Xiang J, Wang Y, Song B, Gu X, Guan L, Wei Y, Li H, Wu X, Xu J, Tu S, Zhang Y, Chen H, Cao B (2020) Clinical course and risk factors for mortality of adult inpatients with COVID-19 in Wuhan, China: a retrospective cohort study. Lancet 395(10229): 1054-1062

16. Edwards S, Small JD, Geratz JD, Alexander LK, Baric RS (1992) An experimental model for myocarditis and congestive heart failure after rabbit coronavirus infection. J Infect Dis 165:134-140

17. Li Y, Guo F, Cao Y, Li L, Guo Y (2020) Insight into COVID-2019 for pediatricians. Pediatr Pulmonol 55:E1-E4

18. Su L, Ma X, Yu H, Zhang Z, Bian P, Han Y, Sun J, Liu Y, Yang C, Geng J, Zhang Z, Gai Z (2020) The different clinical characteristics of corona virus disease cases between children and their families in China - the character of children with COVID-19. Emerg Microbes 
Infect 9(1):707-713. https://doi.org/10.1080/22221751.2020. 1744483

19. Edelson DP, Sasson C, Chan PS, Atkins DL, Aziz K, Becker LB, Berg RA, Bradley SM, Brooks SC, Cheng A, Escobedo M, Flores GE, Girotra S, Hsu A, Kamath-Rayne BD, Lee HC, Lehotzky RE, Mancini ME, Merchant RM, Nadkarni VM, Panchal AR, Peberdy MAR, Raymond TT, Walsh B, Wang DS, Zelop CM, Topjian A (2020) Interim guidance for basic and advanced life support in adults, children, and neonates with suspected or confirmed COVID-19: from the Emergency Cardiovascular Care Committee and Get With the Guidelines ${ }^{\circledR}$-Resuscitation Adult and Pediatric Task Forces of the American Heart Association in collaboration with the American Academy of Pediatrics, American Association for Respiratory Care, American College of Emergency Physicians, The Society of Critical Care Anesthesiologists, and American Society of Anesthesiologists: Supporting Organizations: American Association of Critical Care Nurses and National EMS Physicians. Circulation. doi: https://doi.org/10.1161/CIRCULATIONAHA. 120.047463

20. American College of Cardiology. ACC Clinical Bulletin: Cardiac implications of novel coronavirus (COVID-19). https://www.acc. org/ /media/665AFA1E710B4B3293138D14BE8D1213.pdf [accessed April 16th, 2020]

21. Lakkireddy DR, Chung MK, Gopinathannair R, Patton KK, Gluckman TJ, Turagam M, Cheung J, Patel P, Sotomonte J, Lampert R, Han JK, Rajagopalan B, Eckhardt L, Joglar J, Sandau K, Olshansky B, Wan E, Noseworthy PA, Leal M, Kaufman E, Gutierrez A, Marine JM, Wang PJ, Russo AM (2020) Guidance for cardiac electrophysiology during the coronavirus (COVID-19) pandemic from the Heart Rhythm Society COVID-19 Task Force; Electrophysiology Section of the American College of Cardiology; and the Electrocardiography and Arrhythmias Committee of the Council on Clinical Cardiology, American Heart Association. Heart Rhythm. https://doi.org/10.1016/j.hrthm. 2020.03.028

22. Calcaterra G, Bassareo PP, Barilla F, Martino F, Fanos V, Fedele F, Romeo F (2019) Pulmonary hypertension in paediatrics. A feasible approach to bridge the gap between real world and guidelines. $\mathrm{J}$ Matern Fetal Neonatal Med 19:1-211. https://doi.org/10.1080/ 14767058.2019.1695770

23. Skulstad H, Cosyns B, Popescu BA, Galderisi M, Salvo GD, Donal E, Petersen S, Gimelli A, Haugaa KH, Muraru D, Almeida AG, Schulz-Menger J, Dweck MR, Pontone G, Sade LE, Gerber B, Maurovich-Horvat P, Bharucha T, Cameli M, Magne J, Westwood M, Maurer G, Edvardsen T (2020) COVID-19 pandemic and cardiac imaging: EACVI recommendations on precautions, indications, prioritization, and protection for patients and healthcare personnel. Eur Heart J Cardiovasc Imaging. https://doi.org/10. 1093/ehjci/jeaa072

24. Dong Y, Mo X, Hu Y, Qi X, Jiang F, Jiang Z, Tong S (2020) Epidemiology of COVID-19 among children in China. Pediatrics. https://doi.org/10.1542/peds.2020-0702

25. Di Mascio D, Khalil A, Saccone G, Rizzo G, Buca D, Liberati M, Vecchiet J, Nappi L, Scambia G, Berghella V, D'Antonio F (2020) Outcome of Coronavirus spectrum infections (SARS, MERS, COVID 1-19) during pregnancy: a systematic review and metaanalysis. Am J Obstet Gynecol MFM 25:100107. https://doi.org/ 10.1016/j.ajogmf.2020.100107

26. Zeng L, Xia S, Yuan W, Yan K, Xiao F, Shao J, Zhou W (2020) Neonatal early-onset infection with SARS-CoV-2 in 33 neonates born to mothers with COVID-19 in Wuhan, China. JAMA Pediatr. https://doi.org/10.1001/jamapediatrics.2020.0878

27. Li F, Li W, Farzan M, Harrison SC (2005) Structure of SARS coronavirus spike receptor-binding domain complexed with receptor. Science 309:1864-1868
28. Chen C, Zhou Y, Wang DW (2020) SARS-CoV-2: a potential novel etiology of fulminant myocarditis. Herz 45:230-232. https://doi.org/10.1007/s00059-020-04909-Z

29. Zheng YY, Ma YT, Zhang JY, Xie X (2020) COVID-19 and the cardiovascular system. Nat Rev Cardiol 17:259-260. https://doi. org/10.1038/s41569-020-0360-5

30. Fang L, Karakiulakis G, Roth M (2020) Are patients with hypertension and diabetes mellitus at increased risk for COVID-19 infection? Lancet Respir Med 8:e21. https://doi.org/10.1016/S22132600(20)30116-8

31. Lu R, Zhao X, Li J, Niu P, Yang B, Wu H, Wang W, Song H, Huang B, Zhu N, Bi Y, Ma X, Zhan F, Wang L, Hu T, Zhou H, Hu Z, Zhou W, Zhao L, Chen J, Meng Y, Wang J, Lin Y, Yuan J, Xie Z, Ma J, Liu WJ, Wang D, Xu W, Holmes EC, Gao GF, Wu G, Chen W, Shi W, Tan W (2020) Genomic characterisation and epidemiology of 2019 novel coronavirus: implications for virus origins and receptor binding. Lancet 395:565-574. https://doi.org/10. 1016/S0140-6736(20)30251-8

32. Wan Y, Shang J, Graham R, Baric RS, Li F (2020) Receptor recognition by novel coronavirus from Wuhan: an analysis based on decade-long structural studies of SARS. J Virol ;94(7). doi: https:// doi.org/10.1128/JVI.00127-20

33. Hoffmann M, Kleine-Weber H, Schroeder S, Krüger N, Herrler T, Erichsen S, Schiergens TS, Herrler G, Wu NH, Nitsche A, Müller MA, Drosten C, Pöhlmann S (2020) SARS-CoV-2 cell entry depends on ACE2 and TMPRSS2 and is blocked by a clinically proven protease inhibitor. Cell 181:271-280.e8. https://doi.org/10.1016/ j.cell.2020.02.052

34. Donoghue M, Hsieh F, Baronas E, Godbout K, Gosselin M, Stagliano N, Donovan M, Woolf B, Robison K, Jeyaseelan R, Breitbart RE, Acton S (2000) A novel angiotensin-converting enzyme-related carboxypeptidase (ACE2) converts angiotensin I to angiotensin 1-9. Circ Res 87:e1-e9

35. Bavishi C, Maddox TM, Messerli FH (2020) Coronavirus disease 2019 (COVID-19) infection and renin angiotensin system blockers. JAMA Cardiol. https://doi.org/10.1001/jamacardio.2020.1282

36. Danser AHJ, Epstein M, Batlle D (2020) Renin-angiotensin system blockers and the COVID-19 pandemic: at present there is no evidence to abandon renin-angiotensin system blockers. Hypertension: HYPERTENSIONAHA12015082. doi:https://doi.org/10.1161/ HYPERTENSIONAHA. 120.15082

37. Fang F, Luo XP (2020) Facing 2019 novel coronavirus infections: a pediatrician's thinking. Zhonghua Er Ke Za Zhi 58:E001. https:// doi.org/10.3760/cma.j.issn.0578-1310.2020.0001

38. Brodin P (2020) Why is COVID-19 so mild in children? Acta Paediatr 109:1082-1083. https://doi.org/10.1111/apa.15271

39. Chen N, Zhou M, Dong X, Qu J, Gong F, Han Y, Qiu Y, Wang J, Liu Y, Wei Y, Xia J, Yu T, Zhang X, Zhang L (2020) Epidemiological and clinical characteristics of 99 cases of 2019 novel coronavirus pneumonia in Wuhan, China: a descriptive study. Lancet 395:507-513. https://doi.org/10.1016/S01406736(20)30211-7

40. Biondi-Zoccai G, Landoni G, Carnevale R, Cavarretta E, Sciarretta S, Frati G (2020) SARS-CoV-2 and COVID-19: facing the pandemic together as citizens and cardiovascular practitioners. Minerva Cardioangiol. https://doi.org/10.23736/S0026-4725.20.05250-0

41. Li B, Yang J, Zhao F, Wang X, Liu L, Bi Z, Zhao Y (2020) Prevalence and impact of cardiovascular metabolic diseases on COVID-19 in China. Clin Res Cardiol 109:531-538. https://doi. org/10.1007/s00392-020-01626-9

42. Sakabe M, Yoshioka R, Fujiki A (2013) Sick sinus syndrome induced by interferon and ribavirin therapy in a patient with chronic hepatitis C. J Cardiol Cases 8:173-175

43. Molloy EJ, Bearer CF (2020) COVID-19 in children and altered inflammatory responses. Pediatr Res. https://doi.org/10.1038/ s41390-020-0881-y 
44. Perry M, Townson M, Cottrell S, Fagan L, Edwards J, Saunders J, O'Hare R, Richardson G (2020) Inequalities in vaccination coverage and differences in follow-up procedures for asylum-seeking children arriving in Wales, UK. Eur J Pediatr 179:171-175

45. Hadjipanayis A, Dornbusch HJ, Grossman Z, Theophilou L, Brierley J (2020) Mandatory vaccination: a joint statement of the ethics and vaccination working groups of the European Academy of Paediatrics. Eur J Pediatr 179(4):683-687. https://doi.org/10. 1007/s00431-019-03523-4

46. Bansal M (2020) Cardiovascular disease and COVID-19. Diabetes Metab Syndr 14:247-250

Publisher's note Springer Nature remains neutral with regard to jurisdictional claims in published maps and institutional affiliations. 